\title{
Prevalence of musculoskeletal disorders among Norwegian female biathlon athletes
}

This article was published in the following Dove Press journal:

Open Access Journal of Sports Medicine

23 March 2013

Number of times this article has been viewed

\author{
Håvard $\varnothing$ sterås' \\ Kirsti Krohn Garnæs ${ }^{2}$ \\ Liv Berit Augestad ${ }^{3}$ \\ 'Department of Physical Therapy, \\ Faculty of Health Education and \\ Social Work, Sør-Trøndelag University \\ College, Trondheim, Norway; \\ ${ }^{2}$ Department of Human Movement \\ Science, Norwegian University of \\ Science and Technology, Trondheim, \\ Norway; ${ }^{3}$ Department of Human \\ Movement Science, Norwegian \\ University of Science and Technology, \\ Trondheim, Norway
}

\begin{abstract}
The purpose was to examine musculoskeletal disorders in Norwegian female biathlon athletes (age $\geq 16$ ), both juniors and seniors. The design was a retrospective cross-sectional study. In all, 148 athletes (79.1\%) responded; of these, 118 athletes were 16-21 years (juniors) (77.6\%), and 30 athletes were 22 years or older (seniors) (20.3\%), and mean age was 19.1. A validated questionnaire was used to collect the data. The prevalence of musculoskeletal disorders was $57.8 \%$. The most affected parts were the knee $(23.0 \%$ of the total injuries), calf (12.2\%), ankle/foot (10.8\%), lower back (10.8\%), and thigh (10.1\%). The disorders resulted in training/competition cessation for $73.5 \%$ of athletes, in alternative training for $87.8 \%$. Fifty percent of the athletes had one or several musculoskeletal disorders. Most of the problems occurred preseason, and the duration of symptoms was often prolonged. Few differences between the juniors and seniors were found. This study showed the prevalence of musculoskeletal problems among female biathlon athletes. The results indicate that prevention of lower limb problems must be prioritized, especially during the preseason.
\end{abstract}

Keywords: injuries, cross-country skiing, skating

\section{Introduction}

Biathlon is an endurance sport which combines cross-country skiing and skating technique with shooting. This sport requires high training loads and repetitive type of training through the whole year, and top level performance in biathlon has become more demanding for both sexes, with significant increases in number of races, and total and daily amount of training. ${ }^{1}$ The sport-specific demands may increase the athlete's risk for injuries, fatigue, and overuse problems and sets stringent requirements for rest and nutrition.

Biathlon has traditionally been a male sport, but in the last 10-15 years, the sport has experienced a markedly increased number of female athletes, both at the national and international level. A search for relevant literature revealed a lack of publications related to health issues in biathlon specifically and a limited number of studies related to the prevalence of injuries among female endurance athletes generally. ${ }^{2}$

Several studies among endurance athletes have found a higher prevalence of knee problems and a higher risk for stress fractures among female athletes compared with male athletes. ${ }^{3,4}$ Studies of cross-country skiing in both sexes showed a high prevalence of problems related to overuse compared with acute injuries, ${ }^{5,6}$ which is in accordance with findings in other endurance sports, such as cross-country running, orienteering, and cycling. ${ }^{3}$ Studies of both male and female cross-country skiers have also found an 
increased risk for injuries/disorders in the lower extremity of the body compared with the upper extremity, ${ }^{6}$ and in the lower-back region. ${ }^{5,7,8}$

It is of interest to acquire knowledge regarding injuries and other musculoskeletal problems related to female biathlon, to be able to prevent negative health outcomes, to complete sufficient treatment, and to support high-level performance. Our hypothesis was that this population of athletes has a high prevalence of musculoskeletal disorders and that in order to develop a good preventive intervention program, it was necessary to know more about this. The aim of this study was to examine the prevalence of musculoskeletal disorders among Norwegian female biathlon athletes.

\section{Methods}

\section{Design}

The design of the study employed a retrospective, crosssectional survey that elicited longitudinal data.

\section{Subjects}

All Norwegian female biathlon athletes who had paid the Norwegian Biathlon Federation (NSSF) for license to compete in the 2007 biathlon season were eligible for inclusion in this study. Athletes aged 16-21 years comprised the junior group, and athletes 22 years and older comprised the senior group; the junior and senior age groups were in accordance with those employed by the NSSF. Both groups consisted of athletes at both national and international level of performance.

\section{Instruments and procedures}

A letter was sent to all the athletes who were eligible for inclusion in this study, a total of 187 athletes; 152 juniors and 35 seniors. The mailing contained a request, a consent letter, an information letter, a questionnaire, and a stamped envelope for returning the questionnaire. Reminders were sent by both email and postal service and contained a new consent letter, questionnaire, and envelope with postage. The subjects were identifiable through a number written on the questionnaire, to enable a follow-up study. A total of 152 athletes $(81.3 \%)$, 122 juniors $(80.3 \%)$ and 30 senior $(85.7 \%)$, athletes agreed to participate and returned a completed questionnaire. Of the junior athletes, four were excluded: one because she had quit biathlon 1 year ago; three because they were incorrectly registered by the NSSF as junior and were under 16-years-old. Finally, 148 (79.1\%) participated in this study, $118(77.6 \%)$ junior athletes and $30(85.7 \%)$ senior athletes.

A single questionnaire suitable for the objective of this project was not found, but parts of a questionnaire developed for the Norwegian Olympic and Paralympic Committee and Confederation of Sports Athletes (unpublished data, 1996) was used. The questionnaire composed for this study was tested for validity and reliability, in a pilot study (not shown), with 15 female cross-country skiers aged 16-28 years.

The original questionnaire regarding the athlete's health situation consisted of 38 questions. For the present study, these were selected: Questions 1-4, general information, such as age, weight, height, attendance at ski high school, and use of a training diary; Question 5, volume of total training (skis, roller skis, running, cycling, strength, paddling, etc) and skating-specific training (skis and roller skis) per month; Questions 9 and 10, musculoskeletal disorders (yes/no), training cessation and/or alternative training because of these problems (yes/no), and total duration of training cessation and alternative training; Question 12, identification of musculoskeletal disorders relating to the part of the body affected, duration, and month of occurrence.

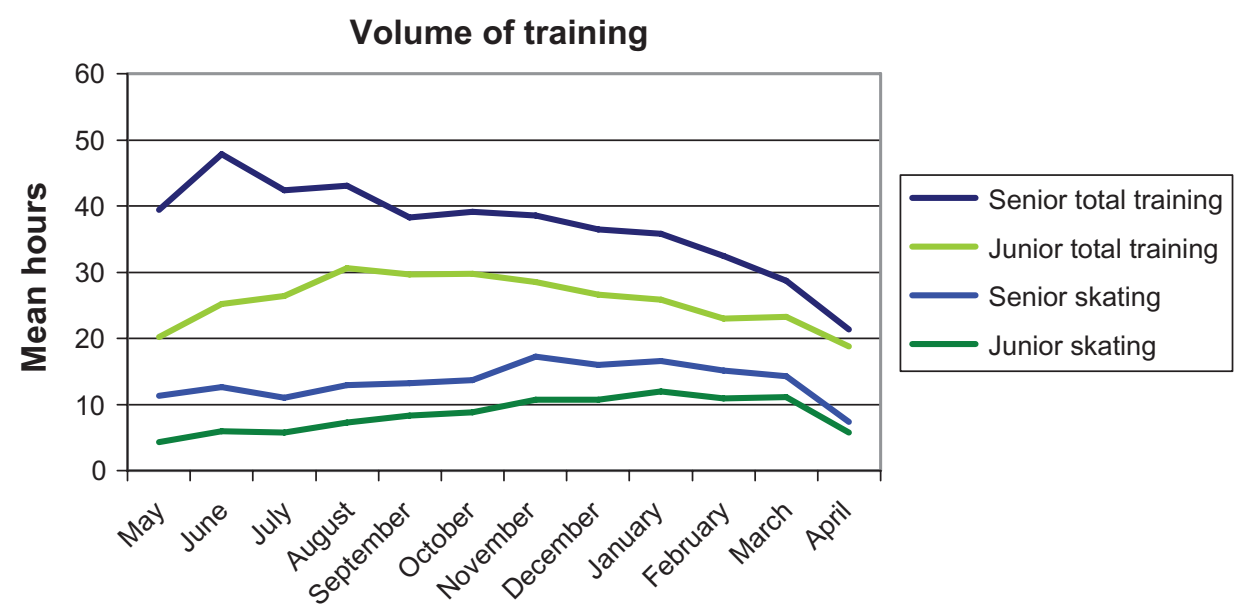

Figure I Mean volume of total training and skating-specific training hours per month, for junior and senior athletes participating in this study. 
The questionnaire was based on self-report; however, several of the musculoskeletal problems reported by the athletes had been diagnosed by medical personnel. In this study and in the questionnaire, musculoskeletal disorder was defined as an injury in or problem related to muscles, tendons, ligaments, bursas, or the skeleton. "Preseason" was defined as the period from May-October, and "ski season" was defined as the period from November-March. Body mass index (BMI) was calculated, using the athletes' height and weight, as $\mathrm{kg} / \mathrm{m}^{2}$. "Volume of training" was defined as hours per month.

\section{Analysis}

All statistical analyses were performed using SPSS/PASW v. 19.0 (IBM, Armonk, NY, USA). Univariate statistical methods were used. The subject characteristics, such as age, weight, height, BMI, the total amount of training, and the amount of skating (skis and roller-skis), are reported as means and confidence interval $(\mathrm{CI}=95 \%)$. The junior and senior group were compared using independent samples $t$-test and the $P$-value (2-tailed) estimated by the $t$-test for equality of means. Factors such as attending ski high school, participating in other sports, and use of a training diary were analyzed by descriptive statistics, with the $P$-value found by Pearson's Chi-square test.

The prevalence of musculoskeletal disorders, body parts affected, number of disorders/injuries per subject, month of occurrence, and duration of symptoms are presented as number of participants and percent. These data were analyzed by descriptive statistics, and the estimation of the $P$-value was done using Pearson's Chi-square test. The most frequently affected body parts were selected and analyzed for month of occurrence and duration. The criterion for defining statistically significant effect was set as $P$-value $\leq 0.05$. The categories "don't know," "no response," and "not applicable" were defined as "missing" in the data material before the analyses were done. Odds ratio (OR), the risk for having a musculoskeletal problem, was calculated as: (exposed cases/all cases)/(unexposed cases/all cases).

\section{Ethics}

The participation in this study was voluntary, and the athletes signed a consent letter. This project was approved by the Regional Medical Committee for Medical Research Ethics, Mid-Norway, and The Data Inspectorate of Norway.

\section{Results}

The mean "volume" (ie, hours/month) of total physical training (cross-country skiing, roller-skis, running, cycling, strength training, etc) during the 2007-2008 season was 337.3 hours (confidence interval $[\mathrm{CI}]=297.3-377.2$ ) for the juniors and 478.3 hours $(\mathrm{CI}=413.8-542.8)$ for the seniors. The mean volume of total skating-specific training (skis and roller-skis) was 114.1 hours $(\mathrm{CI}=98.4-129.9)$ for the juniors and 179.2 hours $(\mathrm{CI}=144.6-213.9)$ for the seniors (Figure 1). The mean age in the total group was 19.1 years, and the oldest athletes were 41-years-old. The senior athletes had a significantly higher volume of total training $(P<0.01)$ and skating-specific training $(P<0.01)$ than did the juniors, during the same season.

August was the month with the highest volume of total training for the juniors (30.6 hours $[\mathrm{CI}=26.2-35.0]$ ); this was June for the seniors (47.8 hours $[\mathrm{CI}=37.7-58.0]$ ). Both groups had the lowest volume of total training in April (juniors: 18.8 hours [CI $=15.2-20.8]$; seniors: 21.3 hours $[C I=15.7-26.9])$. January was the month of highest volume of skating-specific training for the juniors (12.0 hours $[\mathrm{CI}=10.0-13.9])$, whereas this was November for the seniors (17.2 hours $[\mathrm{CI}=12.7-21.8]$ ).

In the total group of female athletes, $57.4 \%(\mathrm{~N}=85)$ reported one or more musculoskeletal disorders; this was $59.3 \%(\mathrm{~N}=70)$ in the junior group and $50.0 \%(\mathrm{~N}=15)$ in the senior group, which were not significantly different $(P=0.33$; $\mathrm{OR}=1.48)$. Among all participants with a musculoskeletal disorder $57.6 \%(\mathrm{~N}=49)$ reported one musculoskeletal disorder, $27.1 \%(\mathrm{~N}=23)$ reported two disorders, $9.4 \%(\mathrm{~N}=8)$ reported three disorders, and $4.7 \%(\mathrm{~N}=4)$ reported four or more disorders. There was no significant difference in number of disorders between the junior and senior group $(P=0.70)$.

The knee $(23 \%, \mathrm{~N}=34)$ was the most frequently affected body part, followed by the calf $(12.2 \%, \mathrm{~N}=18)$, ankle/foot $(10.8 \%, \mathrm{~N}=16)$, lower back $(10.8 \%, \mathrm{~N}=16)$, and the thigh $(10.1 \%, N=15)$ (Figure 2). The number of disorders per body part per subject was not included in these numbers. There was no significant difference between the junior and senior group in the body parts that were most frequently affected, but a higher rate of thigh problems was seen among the juniors $(12.7 \%)$ compared with the seniors (3.3\%).

The main findings regarding duration of musculoskeletal disorders were that: for knee problems, $23.5 \%$ lasted 1-2 weeks and $55.9 \%$ lasted $>4$ weeks; for calf problems, $72.2 \%$ lasted $>4$ weeks; for ankle/foot problems, $31.2 \%$ lasted 1-2 weeks, $37.5 \%$ lasted $>4$ weeks; for lower back problems, $87.5 \%$ : lasted $>4$ weeks; and for thigh problems, $75 \%$ lasted $>4$ weeks. The juniors had significant longer duration of knee problems compared with the seniors $(P=0.04)$. No significant differences in duration of symptoms 
Prevalence of disorders related to part of the body

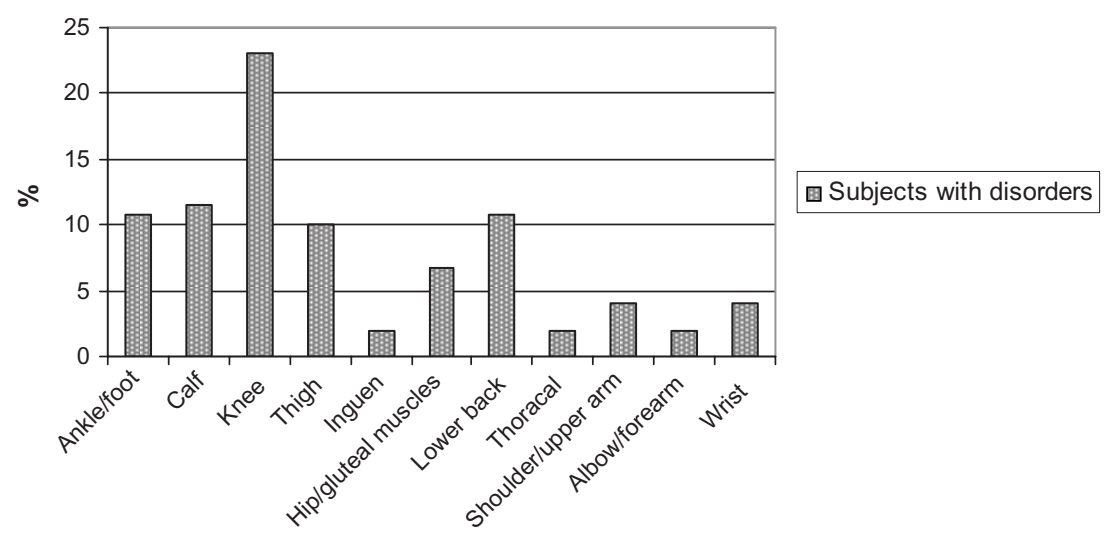

Figure 2 The prevalence of musculoskeletal disorders affecting different parts of the body.

between these two groups were found related to the other body parts. The most frequent occurrence of musculoskeletal disorders was in the preseason $(78.2 \%, \mathrm{~N}=68)$ compared with the ski-season $(21.8 \%, \mathrm{~N}=19)$. May $(20.7 \%, \mathrm{~N}=18)$, with September $(17.2 \%, \mathrm{~N}=15)$ highlighted as the months with highest occurrence of disorders during the period of study. There was no significant difference in month of occurrence between junior and senior groups $(P=0.63)$ (Figure 3).

Most of the athletes with musculoskeletal disorders reported that training/competition was stopped and/or that alternative training was done, because of these problems (Table 1 and Table 2).

\section{Discussion}

Approximately $50 \%$ of the Norwegian female biathlon athletes experienced musculoskeletal disorders during the 2007-2008 season. The current study was based on self-reports, and answers were dependent on each athlete's understanding of the disorder manifestation and their own symptoms. This may have increased the injury rate compared with studies based on disorders diagnosed by medical personnel. Comparison between the junior and the senior athletes was difficult because of a low number of athletes in the senior group. Although there were fewer senior athletes than juniors, the response rate in the senior group was higher. It is important to be aware that most of the biathlon athletes in the current study also participated in other sports. ${ }^{2}$ Therefore, different injury mechanisms, unrelated to participation in biathlon, may have affected this group of athletes and led to musculoskeletal disorders.

Few studies of musculoskeletal problems among biathlon athletes have been found, but it is reasonable to make comparisons with studies of cross-country skiing, which has sport-specific demands closely related to those of biathlon. ${ }^{2}$ Blut et $\mathrm{al}^{2}$ found a significantly higher injury prevalence among female biathlon athletes (54.5\%) compared with male athletes (39.7\%) during the 2008-2009

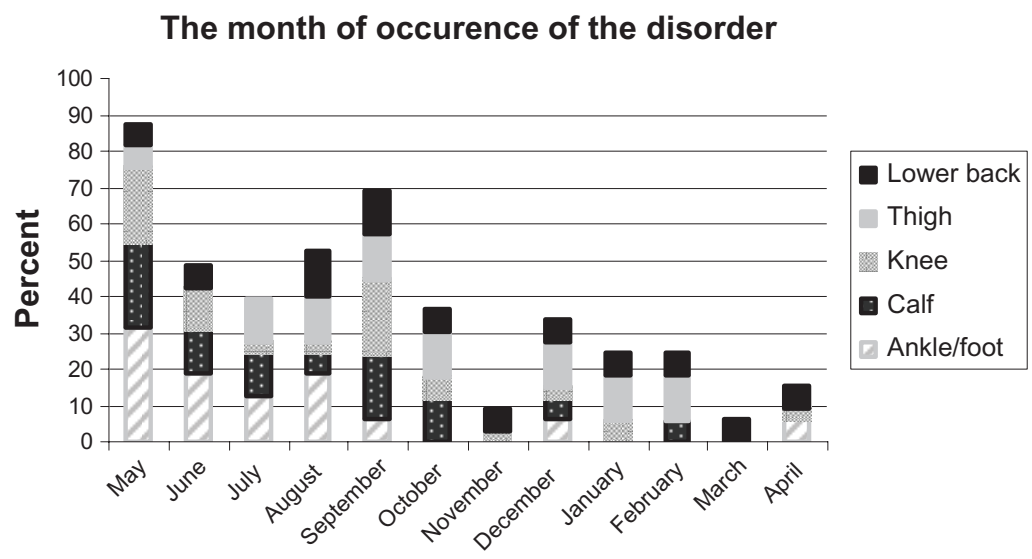

Figure 3 The month of occurrence of the most frequent musculoskeletal disorders. Note: The results are given in percent of athletes with the respective disorder. 
Table I Age, height, weight, BMI, use of training diary, education at ski high school (current or previous seasons), and participation in other sports during the 2007-2008 season

\begin{tabular}{|c|c|c|c|c|c|c|c|}
\hline & \multicolumn{2}{|c|}{$\begin{array}{l}\text { Junior } \\
\mathbf{N}=\text { I I } 8\end{array}$} & \multicolumn{2}{|c|}{$\begin{array}{l}\text { Senior } \\
\mathbf{N}=\mathbf{3 0} \\
\end{array}$} & \multicolumn{2}{|c|}{$\begin{array}{l}\text { All subjects } \\
N=148 \\
\end{array}$} & \multirow{2}{*}{$\begin{array}{l}\text { Differences } \\
\text { junior/senior } \\
\text {-value }^{\mathrm{a}}\end{array}$} \\
\hline & Mean & (SD) & Mean & (SD) & Mean & (SD) & \\
\hline Age & 17.4 & $( \pm 1.26)$ & 25.8 & $( \pm 4.7 \mathrm{I})$ & 19.1 & $( \pm 4.15)$ & 0.000 \\
\hline Height & 168.0 & $( \pm 0.05)$ & 170.0 & $( \pm 0.05)$ & 168.4 & $( \pm 0.05)$ & 0.056 \\
\hline Weight & 60.1 & $( \pm 6.21)$ & 62.0 & $( \pm 5.93)$ & 60.5 & $( \pm 6.18)$ & 0.132 \\
\hline \multirow[t]{2}{*}{ BMI } & 21.3 & $( \pm 1.96)$ & 21.4 & $( \pm 1.68)$ & 21.3 & $( \pm 1.90)$ & 0.728 \\
\hline & $\mathbf{N}$ & (\%) & $\mathbf{N}$ & $(\%)$ & $\mathbf{N}$ & (\%) & $P$-value ${ }^{b}$ \\
\hline Ski high school & 53 & $(45.3)$ & 21 & $(70.0)$ & 74 & $(50.3)$ & 0.016 \\
\hline Other sports & 71 & $(60.7)$ & 9 & $(30.0)$ & 80 & $(54.4)$ & 0.003 \\
\hline Training diary & 97 & $(82.9)$ & 23 & $(76.7)$ & 120 & $(81.6)$ & 0.431 \\
\hline
\end{tabular}

Notes: ${ }^{S}$ Significance based on $t$-test for equality of means; bsignificance based on Pearson Chi-square test.

Abbreviations: BMI, body mass index; SD, standard deviation.

season. However, this was only found among senior athletes. Difficulties may be seen in directly comparing musculoskeletal problems among biathlon athletes and cross-country athletes, because cross-country athletes compete mainly in "classic" technique and to a lesser extent, in "skating technique," whereas biathlon athletes compete only in "skating" technique. The prevalence of musculoskeletal problems found in the current study is in accordance with that found in a study by Alricsson and Werner ${ }^{7}$ of male and female Swedish cross-country skiers attending a ski high school, where $55 \%$ of 117 reported of symptoms/injuries in one or several parts of the body during the preceding 3 months. However, this is a lower prevalence than was claimed among 690 German crosscountry skiers (69.3\%). ${ }^{9}$ Bergstrøm et $\mathrm{al}^{5}$ even found that $96 \%$ of 45 Swedish ski high school athletes reported pain in one or several parts of the body during a season.

In this study of female biathlon athletes, the lower limbs seem to have been more affected by musculoskeletal disorders compared with the upper limbs. This result is in

Table 2 Prevalence and duration of training/competition cessation and alternative training caused by musculoskeletal disorders

\begin{tabular}{|c|c|c|c|c|c|c|c|}
\hline & \multicolumn{2}{|c|}{$\begin{array}{l}\text { Junior } \\
(\mathrm{N}=\mathbf{7 0})\end{array}$} & \multicolumn{2}{|c|}{$\begin{array}{l}\text { Senior } \\
(N=15)\end{array}$} & \multicolumn{2}{|c|}{$\begin{array}{l}\text { All subjects } \\
(\mathrm{N}=\mathbf{8 5})\end{array}$} & \multirow{2}{*}{$\begin{array}{l}\text { Differences } \\
\text { junior/senior } \\
P \text {-value }\end{array}$} \\
\hline & $\mathbf{N}$ & (\%) & $\mathbf{N}$ & (\%) & $\mathbf{N}$ & $(\%)$ & \\
\hline Training/competition cessation & 53 & (77.9) & 8 & $(53.3)$ & 61 & $(73.5)$ & 0.051 \\
\hline Missing & 2 & & 0 & & 2 & & \\
\hline Duration of training cessation & & & & & & & 0.484 \\
\hline $\mathrm{I}-3$ days & 3 & $(5.7)$ & 2 & $(25.0)$ & 5 & $(8.2)$ & \\
\hline 4-7 days & 11 & $(20.8)$ & 2 & $(25.0)$ & 13 & $(2 \mid .3)$ & \\
\hline I-2 weeks & 9 & $(17.0)$ & 2 & $(25.0)$ & 11 & $(I 8.0)$ & \\
\hline $2-3$ weeks & 6 & $(11.3)$ & 0 & $(0.0)$ & 6 & $(9.8)$ & \\
\hline 3-4 weeks & 6 & $(\mathrm{I} \mid .3)$ & 0 & $(0.0)$ & 6 & $(9.8)$ & \\
\hline I-3 months & 8 & $(15.1)$ & I & $(12.5)$ & 9 & $(14.8)$ & \\
\hline$>3$ months & 10 & $(18.9)$ & I & $(12.5)$ & 11 & $(18.0)$ & \\
\hline Missing & 0 & & 0 & & 0 & & \\
\hline Alternative training & 59 & $(88.1)$ & 13 & $(86.7)$ & 72 & $(87.8)$ & 0.882 \\
\hline Missing & 3 & & 0 & & 3 & & \\
\hline Duration of alternative training & & & & & & & 0.134 \\
\hline $\mathrm{I}-3$ days & 3 & $(6.2)$ & 2 & $(15.4)$ & 5 & $(8.2)$ & \\
\hline 4-7 days & 6 & $(12.5)$ & 5 & $(38.5)$ & II & $(18.0)$ & \\
\hline I-2 weeks & 7 & $(14.6)$ & I & $(7.7)$ & 8 & $(13.1)$ & \\
\hline $2-3$ weeks & 2 & $(4.2)$ & I & $(7.7)$ & 3 & $(4.9)$ & \\
\hline 3-4 weeks & 8 & $(16.7)$ & 3 & $(23.1)$ & II & $(18.0)$ & \\
\hline I-3 months & 7 & $(14.6)$ & 0 & $(0.0)$ & 7 & $(11.5)$ & \\
\hline$>3$ months & 15 & $(31.2)$ & I & (7.7) & 16 & $(26.2)$ & \\
\hline Missing & 11 & & 0 & & II & & \\
\hline
\end{tabular}

Note: aSignificance based on Pearson Chi-square test. 
accordance with findings among cross-country skiers. ${ }^{6,10}$ The lower limbs are major contributors to power generated in skating, ${ }^{11,12}$ and are also exposed to higher training loads through other training, such as classic skiing, running and bicycling, compared with the upper limbs.

Especially knee disorders, but also ankle/foot and calf disorders, appear to be a problem for many female biathlon athletes. These problems often occur during preseason when athletes stop skiing and start to use running and cycling as the major part of their training. The majority of injuries may be caused from training activities such as running. Furthermore, the skating technique requires knee and ankle/foot stability in the push-off phase, and knee pain may be produced if this stability is insufficient. Biathlon is an endurance sport and requires a high amount of relatively repetitive training and may be at risk for the same type of injuries found among other endurance athletes. In the present study, a high proportion of junior biathlon athletes reported thigh problems during the season under study, and muscular soreness and reduced muscle function in the thigh may be a symptom of an overtraining syndrome or unexplained underperformance. ${ }^{9}$ Budgett et $\mathrm{al}^{13}$ claim that unexplained underperformance occurs in around $10 \%-20 \%$ of elite endurance athletes, which is in accordance with the findings in the current study.

Lower-back problems are often thought to be a problem among athletes who perform cross-country skiing. This problem was present among the female biathlon athletes studied, but the prevalence was lower compared with that found in studies of cross-country skiers. Among both male and female Norwegian and Swedish cross-country skiers, 44.2\%, 63\%, and $67.0 \%$ of the athletes have reported low-back pain. ${ }^{5}$ In one study, low-back pain seemed to occur more often in connection with classic technique rather than in connection with skating technique. ${ }^{7}$ Biathlon athletes have a smaller volume of classic technique compared with cross-country skiers because in biathlon, only skating technique is used in competition, and classic technique is used only for low-intensity and alternative training. The results of the current study of female biathlon athletes showed a higher prevalence of low-back pain among the junior athletes, which is in accordance with the findings of Bergstrøm et al, ${ }^{5}$ who claimed that lower-back problems were more frequent among the youngest athletes.

Most of the musculoskeletal problems reported among the female biathlon athletes occurred during preseason, except for the thigh and lower-back problems, which seemed to be present during the competition season. This may be due to the changeover period from skiing on snow to increased running, skating on roller skies, and cycling, between April and May, when moving patterns may be unused, the training loads may increase to fast. However, Bahr et $\mathrm{al}^{8}$ found, in their study of cross-country skiers, a higher rate of low-back pain during periods with high-training and/or competition load, which also support the findings in the current study, of low-back problems occurring during the winter. However, a study by Reinking and Hayes ${ }^{9}$ of cross-country runners didn't find any significant relationship between training distance and exercise-induced musculoskeletal problems. Many of the calf and the knee problems in the current study occurred in May, when the mean volume of training was relatively low. These findings indicate different injury mechanisms affecting the different type of disorders. In September, many athletes increase their training intensity and volume of roller-ski training. These changes in training may lead to a higher risk of musculoskeletal problems.

A prolonged duration of symptoms, duration of alternative training, and training/competition cessation because of musculoskeletal disorders was found among the female biathlon athletes and may indicate severe or chronic musculoskeletal problems. Most of the athletes with musculoskeletal injuries reported either a stopping of training/competition and/or alternative training because of musculoskeletal problems, but the rate was higher for alternative training. The prevalence of training/competition cessation was high compared with that in the study by Bahr et $\mathrm{al}^{8}$ on cross-country skiers, where they reported $19.1 \%$ missed training because of low-back pain. This may indicate more severe disorders among juniors, but it may also indicate that the seniors, to a larger extent, choose alternative training and try to avoid training/competition cessation, which may have a major effect on biathlon top-level performance.

An important strength of the current study is that all the female biathlon athletes registered in the NSSF license list were eligible for inclusion in the study. Further, the response rate was relatively high, and the total number of participants was high compared with other studies of endurance athletes. Therefore, the results were less sensitive to individual variations and gave more precise information. Like several of the studies of cross-country skiing, this study included both athletes attending and not attending ski high school, and well represents the total group of competing biathlon athletes in Norway, including athletes with differences in training and social environment. The majority of the participants kept a training diary, which improved their memory of musculoskeletal problems during the season.

A limitation of the study is that the information was based on the athletes' self-reports, not diagnosis, and this 
may influence the value of the information. The numbers of participants in the senior group was low compared with the junior group, and this may have affected the $P$-value estimation and reduced the validity of the data. The age difference (16-40 years) in the group of participants may cause a risk for participants' semantic understanding of the questions and the definitions. Further, a natural selection of the fittest athletes may be present in biathlon, as in other sports; thus, the athletes who are still participating in biathlon at senior age may be the athletes with good health and less severe musculoskeletal problems. In studying the athletes for only one season, this scenario may have reduced the actual prevalence of musculoskeletal disorders in this group.

Future studies should try to examine specific types of musculoskeletal disorders and their severity in the female biathlon sport and cross-country skiing, to better initiate prevention. The relationship between musculoskeletal problems and the volume and type of training, and its variation through the year, should also be investigated. Comparison of injury mechanisms in males and females should also be investigated, in order to better plan a type of training that is adjusted for sex and age. Musculoskeletal disorders may lead to dropout from the sport and to reduced physical fitness and mental well-being. Optimal health is important for athletes, for optimal performance in sport and for optimal daily living in the future.

\section{Conclusion}

In summary, approximately half of the athletes included in this study had one or more musculoskeletal disorders. The knee was the part of the body most frequently affected, and most of the musculoskeletal problems occurred in preseason, mainly in May and September. Many of the musculoskeletal problems were of prolonged duration, which may indicate more severe disorders. Many of the female biathlon athletes reported either cessation of training/competition or doing alternative training because of their problems, which may affect many athletes' ability to perform. Due to requirements of high- and repetitive training loads, often at an early age, the risk of disorders related to overload are present. The lower limbs seem to be more often affected by problems, and this may indicate that the different exercises used in training stress the same structures. The month of occurrence of symptoms differed somewhat between the body parts, indicating different mechanisms provoking these problems. The results of the study indicate that prevention of lower-limb problems must be prioritized, especially in the preseason. These clinical findings should be translated into training plans and injury prevention, starting at an early age.

\section{Disclosure}

The authors report no conflicts of interest in this work.

\section{References}

1. Manfredini F, Manfredini R, Carrabre JE, et al. Competition load and stress in sports: a preliminary study in biathlon. Int J Sports Med. 2002;23(5):348-352.

2. Blut D, Santer S, Carrabre J, Manfredini F. Epidemiology of musculoskeletal injuries among elite biathletes: a preliminary study. Clin J Sport Med. 2010;20(4):322-324.

3. Cosca DD, Navazio F. Common problems in endurance athletes. Am Fam Physician. 2007;76(2):237-244.

4. Joy EA, Campbell D. Stress fractures in the female athlete. Cur Sport Med Reports. 2005;4(6):323-328.

5. Bergstrøm KA, Brandseth K, Fretheim S, Tvilde K, Ekeland A. Back injuries and pain in adolescents attending a ski high school. Knee Surg Sports Traumatol Arthrosc. 2004;12(1):80-85.

6. Frank BC. [Risk of injuries, symptoms of excessive strain and preventive possibilities in cross-country skiing. A comparison between classical technique and skating technique]. Sportverletz Sportschaden. 1995;9(4):103-108. German.

7. Alricsson M, Werner S. Self-reported health, physical activity and prevalence of complaints in elite cross-country skiers and matched controls. J Sports Med Phys Fitness. 2005;45(4):547-552.

8. Bahr R, Andersen SO, Løken S, Fossan B, Hansen T, Holme I. Low back pain among endurance athletes with and without specific back loadinga cross-sectional survey of cross-country skiers, rowers, orienteerers, and nonathletic controls. Spine (Phila Pa 1976). 2004;29(4):449-454.

9. Reinking MF, Hayes AM. Intrinsic factors associated with exerciserelated leg pain in collegiate cross-country runners. Clin J Sport Med. 2006;16(1):10-14.

10. Butcher JD, Brannen SJ. Comparison of injuries in classic and skating Nordic ski techniques. Clin J Sport Med. 1998;8(2):88-91.

11. Bilodeau B, Rundell KW, Roy B, Boulay MR. Kinematics of crosscountry ski racing. Med Sci Sports Exerc. 1996;28(1):128-138.

12. Mikkola JS, Rusko HK, Nummela AT, Paavolainen LM, Häkkinen K. Concurrent endurance and explosive type strength training increases activation and fast force production of leg extensor muscles in endurance athletes. J Strength Cond Res. 2007;21(2):613-620.

13. Budgett R, Newsholme E, Lehmann M, et al. Redefining the overtraining syndrome as the unexplained underperformance syndrome. Br J Sports Med. 2000;34(1):67-68. 


\section{Publish your work in this journal}

Open Access Journal of Sports Medicine is an international, Visit http://www.dovepress.com/testimonials.php to read real quotes peer-reviewed, open access journal publishing original research, from published authors.

reports, reviews and commentaries on all areas of sports

medicine. The manuscript management system is completely

online and includes a very quick and fair peer-review system.

Submit your manuscript here: http://www.dovepress.com/open-access-journal-of-sports-medicine-journal 